\title{
Fractionated radiation therapy stimulates anti-tumor immunity mediated by both resident and infiltrating polyclonal T-cell populations when combined with PD1 blockade
}

DOI:

10.1158/1078-0432.CCR-16-1673

\section{Document Version}

Accepted author manuscript

Link to publication record in Manchester Research Explorer

\section{Citation for published version (APA):}

Dovedi, S., Cheadle, E., Popple, A. L., Poon, E., Morrow, M., Stewart, R., Yusko, E. C., Sanders, C. M., Vignali, M., Emerson, R. O., Robins, H. S., Wilkinson, R. W., Honeychurch, J., \& Illidge, T. (2017). Fractionated radiation therapy stimulates anti-tumor immunity mediated by both resident and infiltrating polyclonal T-cell populations when combined with PD1 blockade. Clinical Cancer Research, 23(18), 5514-5526. https://doi.org/10.1158/10780432.CCR-16-1673

\section{Published in:}

Clinical Cancer Research

\section{Citing this paper}

Please note that where the full-text provided on Manchester Research Explorer is the Author Accepted Manuscript or Proof version this may differ from the final Published version. If citing, it is advised that you check and use the publisher's definitive version.

\section{General rights}

Copyright and moral rights for the publications made accessible in the Research Explorer are retained by the authors and/or other copyright owners and it is a condition of accessing publications that users recognise and abide by the legal requirements associated with these rights.

\section{Takedown policy}

If you believe that this document breaches copyright please refer to the University of Manchester's Takedown Procedures [http://man.ac.uk/04Y6Bo] or contact uml.scholarlycommunications@manchester.ac.uk providing relevant details, so we can investigate your claim.

\section{OPEN ACCESS}


Fractionated RT modulates the local TCR repertoire

Fractionated radiation therapy stimulates anti-tumor immunity mediated by both resident and infiltrating polyclonal T-cell populations when combined with PD1 blockade

Simon J. Dovedi ${ }^{1,2}$, Eleanor J. Cheadle ${ }^{1}$, Amy L. Popple ${ }^{1}$, Edmund Poon ${ }^{2}$, Michelle Morrow $^{2}$, Ross Stewart ${ }^{2}$, Erik C. Yusko ${ }^{3}$, Catherine M. Sanders ${ }^{3}$, Marissa Vignali ${ }^{3}$, Ryan O. Emerson ${ }^{3}$, Harlan S. Robins ${ }^{4}$, Robert W. Wilkinson ${ }^{2 *}$, Jamie Honeychurch ${ }^{1 *}$, Timothy M. Illidge ${ }^{1 *}$.

${ }^{1}$ Targeted Therapy Group, Targeted Therapy Group, Division of Molecular and Clinical Cancer Sciences, Manchester Cancer Research Centre, Christie Hospital, Manchester Academic Health Sciences Centre, United Kingdom.

${ }^{2}$ MedImmune Ltd, Granta Park, Cambridge, United Kingdom.

${ }^{3}$ Adaptive Biotechnologies, Seattle, Washington, United States of America.

${ }^{4}$ Fred Hutchinson Cancer Research Center, Seattle, Washington, United States of America.

* authors contributed equally.

Running title: Fractionated RT modulates the local TCR repertoire

Corresponding authors:

Dr. Simon J. Dovedi. Email: Simon.Dovedi@ics.manchester.ac.uk /

DovediSi@MedImmune.com, MedImmune Ltd, Granta Park, Cambridge, CB21 6GH, United Kingdom.

Prof. Tim Illidge. Email: Tim.Illidge@,ics.manchester.ac.uk, Targeted Therapy Group, Division of Molecular and Clinical Cancer Sciences, Manchester Cancer Research Centre, Paterson Building, Wilmslow Road, Manchester, M20 4BX, United Kingdom.

Financial support

This work was supported by a grant from Cancer Research UK (A17737) to T.M. Illidge, J. Honeychurch, S.J. Dovedi, E.J. Cheadle, A.L. Popple and a grant from MedImmune to T.M. Illidge and S.J. Dovedi. 
Translational Relevance. Radiotherapy (RT) is well documented to be immunogenic; however, systemic anti-tumor immune responses outside of the irradiated tumor field, termed the "abscopal effect", are rare in patients. The lack of abscopal effect is poorly understood, particularly in the context of low-dose daily fractionated RT, the most common regimen used in clinical practice. We demonstrate that 5 daily fractions of 2 Gy induces a polyclonal T-cell response at the irradiation site which is dominated by the expansion of pre-existing T-cell clones. However, systemic anti-cancer immunity appears to be limited locally by adaptive immunological resistance which can be overcome by blockade of the PD-1/PD-L1 pathway leading to long-term tumor control. Furthermore, whilst T-cells resident in the tumor prior to RT are important, newly-infiltrated polyclonal T-cell populations are required for maximal systemic tumor control. These results provide important new insights for clinical translation to improve outcomes using RT through combination with $\alpha$ PD-1/PD-L1 mAb. 
Fractionated RT modulates the local TCR repertoire

\begin{abstract}
Purpose: Radiotherapy (RT) is a highly effective anti-cancer treatment forming part of the standard of care for the majority of patients, but local and distal disease recurrence remains a major cause of mortality. RT is known to enhance tumor immunogenicity; however, the contribution and mechanisms of RT induced immune responses are unknown.
\end{abstract}

Experimental Design: The impact of low-dose fractionated RT ( 5 x 2 Gy) alone and in combination with $\alpha \mathrm{PD}-1 \mathrm{mAb}$ on the tumor microenvironment was evaluated by flow cytometry and next-generation sequencing (NGS) of the T-cell receptor (TCR)repertoire. A dual-tumor model was used, with fractionated RT delivered to a single tumor site to enable evaluation of the local and systemic response to treatment and ability to induce abscopal responses outside the radiation field.

Results: We show that fractionated RT leads to T-cell infiltration at the irradiated site; however, the TCR landscape remains dominated by polyclonal expansion of preexisting T-cell clones. Adaptive resistance via the PD-1/PD-L1 pathway restricts the generation of systemic anti-cancer immunity following RT which can be overcome through combination with $\alpha \mathrm{PD}-1 \mathrm{mAb}$ leading to improved local and distal tumor control. Moreover, we show that effective clearance of tumor following combination therapy is dependent on both T-cells resident in the tumor at the time of RT and infiltrating T-cells.

Conclusions: These data provide evidence that RT can enhance T-cell trafficking to locally-treated tumor sites and augment pre-existing anti-cancer T-cell responses with the capacity to mediate regression of out-of-field tumor lesions when delivered in combination with $\alpha \mathrm{PD}-1 \mathrm{mAb}$ therapy. 
Fractionated RT modulates the local TCR repertoire

\section{Introduction}

Radiation Therapy (RT) is delivered to approximately $50 \%$ of all cancer patients, improving local disease control and reducing recurrence (1-3). RT can modulate the tumor microenvironment in several ways to enhance immunogenicity including modulation of class I MHC and novel peptide antigen expression on tumor cells (4); generation of type-I IFN (5-7); activation of the complement pathway (8); induction of immunogenic cell death (9); and direct effects on immune effector cells (10). Irradiated tumor cells may act as an 'in situ vaccine' through the provision of increased tumor-associated antigens (TAAs), damage-associated molecular patterns (DAMPs), and modulation of the tumor microenvironment promoting DC recruitment and T-cell priming (4,7,11-14). However systemic anti-tumor immune responses outside of the irradiated tumor field termed the "abscopal effect" are rare in routine clinical practice. Furthermore tumor recurrence frequently occurs following RT and remains the leading cause of patient mortality. Therefore, in the clinic, RT alone appears to be generally insufficient to elicit durable, therapeutic anti-tumor immunity (15).

The PD-1/PD-L1 axis is known to mediate peripheral tolerance and attenuation of acute inflammatory responses through modulation of T-cell receptor (TCR) signal transduction, metabolic reprogramming, anergy and apoptosis (16-18). Furthermore, we and others have previously shown across a range of tumor models that signaling through the PD-1/PD-L1 pathway can limit the ability of RT to generate systemic immune responses (19-21). In most of these preclinical studies enhanced tumor immune responses have been generated by high-doses of hypofractionated RT in combination with a range of immunomodulatory agents $(19,21-25)$. In contrast, the 
potential effects on local and systemic T-cell responses of low-dose daily

fractionation as routinely delivered using a series of daily fractionated doses (1.8-2

Gy) are less well studied. Here we have investigated how daily fractionation

modulates the TCR repertoire diversity within the irradiated tumor and how this may be modified with RT in combination with $\alpha \mathrm{PD}-1 \mathrm{mAb}$ to result in a systemic immune response. By sequencing the CDR3 regions of TCR $\beta$ in both irradiated and out-offield tumors, and in peripheral blood, we reveal that RT leads to local expansion of pre-existing T-cell clones within the tumor which dominate the TCR repertoire. In contrast, there was little evidence of T-cell clonal expansion as a consequence of RTinduced DNA-damage with all of the dominant T-cell clones present in both the irradiated and out-of-field tumors following treatment with RT and $\alpha$ PD- $1 \mathrm{mAb}$. In addition, we show that the immunological effects of fractionated RT appear to be limited to the irradiated tumor site through adaptive upregulation of PD-L1. Importantly, blockade of the PD-1/PD-L1 signaling axis circumvents this local immunosuppression facilitating the generation of systemic anti-cancer immunity capable of mediating distal tumor regression. These observations provide new mechanistic insights into the impact of daily fractionated RT on the generation of adaptive anti-tumor immunity.

\section{Materials and Methods}

\section{Mice and cell lines}

BALB/c and C57B1/6 mice were obtained from Harlan, U.K. Animal experiments were approved by a local ethical committee and performed under a United Kingdom Home Office license. CT26 murine colon carcinoma cells (ATCC) and 4434 cells isolated from $\mathrm{BRAF}^{\mathrm{V} 600 \mathrm{E}} \mathrm{p} 16^{-/-}$mice (Richard Marais, Cancer Research 
UK Manchester Institute, Manchester, United Kingdom) were maintained in DMEM, supplemented with $10 \%$ FCS, 1 \% L-glutamine (Invitrogen, U.K.). Upon receipt, cells were cultured for up to 4 passages, screened to confirm the absence of Mycoplasma contamination by PCR and aliquots frozen in liquid nitrogen to create a batch of authenticated stock lines. Cell lines were defrosted and cultured to limited passage for one to two weeks prior to implantation with regular re-screening for Mycoplasma contamination. Mice were housed under specific pathogen free conditions in Tecniplast 1284 IVC cages holding a maximum of 7 animals with aspenchips-2 bedding, sizzlenest nesting material, and a cardboard tunnel. Mice were housed on a 12/12 light/dark cycle and were given filtered water and fed ad libitum on Teklad Global $19 \%$ protein extruded rodent diet.

\section{Tumor therapy}

Mice were inoculated sub-cutaneously (s.c.) with $5 \times 10^{5}$ CT26 cells or $5 \times 10^{6}$ 4434 cells at one or more distinct sites. Irradiations were performed 7-10 days after the primary tumor was inoculated (when primary tumors were at least $100 \mathrm{~mm}^{3}$ ) using a Pantak HF-320 320 kV x-ray unit (Gulmay Medical, U.K.). The machine was operated at $300 \mathrm{kV}, 9.2 \mathrm{~mA}$, with filtration fitted in the $\mathrm{x}$-ray beam to give a radiation quality of $2.3 \mathrm{~mm} \mathrm{Cu}$ half-value layer. Mice were positioned at a distance of $350 \mathrm{~mm}$ from the x-ray focus, where the dose rate was $0.80 \mathrm{~Gy} / \mathrm{min}$ and treated using tangential beam delivery. Administration of $\alpha \mathrm{PD}-1$ (clone RMP1-14), $\alpha \mathrm{PD}-\mathrm{L} 1$ (clone 10F.9G2) or isotype control mAb (Biolegend, U.K.) commenced on day 1 of the fractionated RT cycle via intra-peritoneal (i.p.) injection $3 \mathrm{qw}$ for 1 week at a dose of 
$10 \mathrm{mg} / \mathrm{kg}$ in a dose volume of $100 \mu \mathrm{l} / 10 \mathrm{~g}$ in PBS. Tumor volume (up to $1200 \mathrm{~mm}^{3}$ ) was the primary endpoint for efficacy studies. Peripheral blood was sampled during therapy to confirm cellular depletion. Administration of FTY-720 (Fingolimod; Enzo Life Sciences, UK) commenced either the day prior to tumor inoculation or the day prior to the start of RT and was delivered by oral gavage at a dose of $25 \mu \mathrm{g} /$ mouse in a dosing volume of $200 \mu$ l. Subsequent daily administration was continued for 30 days (after the start of RT) at a dose of $5 \mu \mathrm{g}$ /mouse in a dosing volume of $100 \mu \mathrm{l}$ as previously described (26).

For tumor rechallenge experiments, long-term surviving (LTS) mice were implanted with tumor cells at a site distal to the original tumor a minimum of 80 days after previous tumor implantation. Experimental groups contained at least 5 mice/group and are representative of at least 2 independent experiments.

\section{Measurement of cytokine production by $\mathrm{CD8}^{+} \mathrm{T}$-cells isolated from long-term surviving mice}

Splenocytes were isolated from either LTS or control mice and co-cultured for 5 days with either irradiated tumor cells ( $50 \mathrm{~Gy}$ ) or $1 \mu \mathrm{mol} / \mathrm{ml}$ of the $\mathrm{H} 2-\mathrm{Ld}$ restricted peptides SPSYVYHQF (AH1) or TPHPARIGL ( $\beta$-galactosidase) (Anaspec, U.K.). Cells were restimulated at a 1:1 ratio with 50 Gy irradiated CT26 cells for 16 hours in the presence of $1 \mathrm{ul} / \mathrm{ml}$ Brefeldin A (BD Pharmingen, U.K.) and $100 \mathrm{IU} / \mathrm{ml}$ human recombinant IL-2 (Chiron, NL) as described previously (27). Experimental groups contained at least 4 mice and are representative of 2 independent experiments.

\section{Tumor and immune cell phenotyping by flow cytometry}


Fractionated RT modulates the local TCR repertoire

To obtain single cell suspensions, tumors were processed using a gentle MACS dissociator and a murine tumor dissociation kit (Miltenyi Biotec, U.K.). For analysis, non-specific binding was blocked as described above and expression of CD4, CD8 (BD Biosciences, U.K.), CD45, CD11b, Gr1, PD-1 and PD-L1 examined by multi-parameter flow cytometry (all eBioscience unless otherwise stated). For analysis, live cells were gated (by vital dye exclusion, Invitrogen, U.K.) and populations phenotyped (as described above). An example of the gating strategy employed for selection of either $\mathrm{CD} 45^{-}, \mathrm{CD} 45^{+}$or $\mathrm{CD} 45^{+} \mathrm{CD} 11 \mathrm{~b}^{+} \mathrm{Gr} 1^{+}$cells is provided in Supplemental Fig. 1.

\section{Immunosequencing of the TCR- $\beta$ expressing repertoire in peripheral blood and}

tumors. Immunosequencing of the CDR3 regions of murine TCR $\beta$ chains was performed on samples isolated 7 days after the last dose of RT (along with timematched control cohorts and those treated with $\alpha \mathrm{PD}-1 \mathrm{mAb}$ ) using the ImmunoSEQTM Assay (Adaptive Biotechnologies, Seattle, WA). This assay uses 54 forward $\mathrm{V}$ gene primers and 13 reverse $\mathrm{J}$ gene primers which are employed in a biascontrolled multiplexed PCR reaction to amplify the variable region of TCRB chains. Synthetic control templates were also spiked into each sample, thereby enabling quantitation of input TCRB templates from the read counts (28). Sequences were collapsed and filtered in order to identify and quantitate the abundance of each unique TCR $\beta$ CDR3 region for further analysis $(28,29)$.

\section{Statistical Analyses of TCR- $\beta$ sequencing results}


Fractionated RT modulates the local TCR repertoire

The clonality metric is defined as 1- Peilou's evenness and is calculated as:

$$
1-\frac{\sum_{i}^{N} p_{i} \ln \left(p_{i}\right)}{\ln (N)}
$$

Clonality values range from 0 to 1 and describe the shape of the frequency distribution: clonality values approaching 0 indicate a very even distribution of frequencies, whereas values approaching 1 indicate an increasingly asymmetric distribution in which a few clones are present at high frequencies. To estimate the fraction of T-cells in the tissue samples, we considered 6.5 pg of DNA per diploid cell, which is equal to approximately 154 productive TCR loci per ng of DNA, and normalized the total T-cell estimates in each sample to the amount of input DNA multiplied with the value of 154 productive TCR loci per ng of input DNA. Pair-wise comparisons within therapy cohorts (i.e. tumor 1 vs. tumor 2) were performed using a paired t-test. For comparisons across multiple therapy groups we used the nonparametric Kruskal-Wallis test. We identified clones with significantly different abundance in two samples using a Fisher's exact test with Benjamini-Hochberg corrected p-values such that false-discovery-rates were held at $5 \%$ (30).

\section{Results}

Fractionated RT in combination with $\alpha$ PD-1 mAb generates systemic anti-cancer

\section{immunity}

Low doses of fractionated RT (delivered as 5 daily fractions of 2 Gy) resulted in transient tumor control followed by regrowth in the majority of mice bearing either CT26 or 4434 tumors. In both models, local tumor control following treatment with fractionated RT can be improved when combined with mAb's targeting the PD-1/PDL1 pathway (Fig. 1A and B). Moreover, long-term surviving (LTS) mice that undergo a complete response following combination therapy are able to completely reject 
tumors following rechallenge (Fig. 1C. P $<0.01$ Log-rank; Mantel-Cox test).

Furthermore, in responding mice we detected an increased frequency of antigenspecific memory $\mathrm{CD} 8^{+}$T-cells capable of IFN $\gamma$ expression following co-culture with either irradiated CT26 cells or a CT26 tumor-associated peptide antigen (AH1: SPSYVYHQF) but not with a control peptide ( $\beta$-galactosidase: TPHARIGL) (Fig. 1D). To address the impact of RT dose and fractionation on therapeutic response RT was also administered as a hypofractionated regimen (12 Gy in 3 fractions) or as a single dose (7 Gy) in combination blockade of the PD-1/PD-L1 axis (Fig. 1E). Importantly, our data reveal similar combinatorial activity for these different RT dosing regimens.

Dual tumor-bearing mice were used to determine whether fractionated RT delivered to a single tumor could lead to 'abscopal' responses in out-of-field tumors. We found that low doses of fractionated RT resulted in transient local tumor control followed by regrowth in the majority of mice treated. However, complete tumor regression was observed in $18.8 \%(3 / 16)$ mice at the irradiated site. Complete regression of the out-of-field tumor following RT was a rare event (observed in $12.5 \%, 2 / 16$ mice), occurring only in mice where the response of the irradiated tumor was such that the mice survived to the study endpoint (day 60) (Fig.2A for experimental schema, 2B and Supplemental Fig. 2A). To determine whether local treatment with an ablative dose of RT would be more effective at generating out-offield responses we treated mice locally with $10 \mathrm{~Gy}$ RT (which led to complete responses in 4/7 (57\%) tumors. Our data demonstrate that treatment with ablative doses of RT alone were insufficient to generate systemic anti-cancer immune responses capable of mediating complete regression of out-of-field tumors with all 
Fractionated RT modulates the local TCR repertoire

mice exhibiting progressive tumour growth at the out-of-field tumor site (Supplemental Fig. 2B).

In contrast, RT delivered concurrently with $\alpha \mathrm{PD}-1 \mathrm{mAb}$ led to the regression of both the irradiated and out-of-field tumors with $>70 \%$ of mice undergoing complete responses (Fig. 2B). These data demonstrate that the combination of fractionated RT and $\alpha \mathrm{PD}-1 \mathrm{mAb}$ generates systemic anti-tumor responses and tumor control in both irradiated and out-of-field tumors.

\section{Combination therapy leads to convergence of tumoral and systemic TCR} repertoires

In order to understand how these treatments impacted the clonal populations of tumor resident T-cells we sequenced the TCR repertoire 7 days after the last dose of RT. Analysis of the TCR- $\beta$ sequences confirmed that fractionated RT increases the frequency of T-cells in the irradiated but not out-of-field tumor (Fig. 2C). Whilst TCR quantitation does not distinguish between tumor-resident proliferating T-cells or infiltrating T-cells, increased overlap between the TCR repertoire of the irradiated (but not the out-of-field) tumor and that of peripheral blood suggests that T-cell infiltration occurs after local fractionated RT (Fig. 2D). When delivered as a monotherapy, $\alpha \mathrm{PD}-1 \mathrm{mAb}$ did not enhance $\mathrm{T}$-cell content in either tumor relative to the NT mice. In contrast, concurrent RT and $\alpha \mathrm{PD}-1 \mathrm{mAb}$ therapy resulted in increased T-cell infiltration/expansion in both the irradiated and out-of-field tumors relative to NT mice or $\alpha$ PD-1 mAb-treated mice (Fig. 2C, D).

We next examined the impact of these treatments on the clonality of TCR repertoires at the different tumor sites. We found that monotherapy with $\alpha \mathrm{PD}-1 \mathrm{mAb}$ did not alter T-cell clonality in either the local or distal tumor when compared to NT 
Fractionated RT modulates the local TCR repertoire

controls. In contrast, RT-treated mice had increased TCR repertoire clonality in the irradiated but not out-of-field tumor when compared to either NT or $\alpha$ PD-1 mAbtreated mice (Fig. 2E). Moreover, RT increased the number of unique TCRs (thereby increased the diversity of the TCR repertoire) in the irradiated but not out-of-field tumor when compared to NT controls (Fig. 2F). The largest increase in TCR diversity in both the irradiated and out-of-field tumors occurred in mice treated with RT/ $/ \mathrm{PD}-1$ $\mathrm{mAb}$ therapy, demonstrating that this combination generated an immunologic response that extended beyond the RT-treatment field. However, the precise contribution of these individual T-cell clones to tumor control remains unknown.

Analysis of clone sharing and dynamics between the irradiated and out-offield tumors (tumor \#1 and \#2 respectively) revealed that most TCR clones and all high abundance clones ( $>10$ copies detected) were present in both tumors in the NT mice (Fig. 3A, first panel). Moreover, the frequencies of individual clones in both tumor repertoires showed a strong concordance (slope $\left.=0.85, R^{2}=0.94\right)$. These observations indicate that similar TCR repertoires, derived from common progenitor clones were established in both tumors prior to therapy. Similar results were observed in the mice treated with $\alpha \mathrm{PD}-1 \mathrm{mAb}$ as a monotherapy (slope $\left.=0.90, R^{2}=0.95\right)($ Fig $3 \mathrm{~A}$, second panel), which is consistent with the lack of T-cell infiltration/expansion observed in either tumor (Fig. 2C). In contrast, fractionated RT led to preferential clonal expansion in the irradiated tumor and infiltration of many unique clones (clones shown below the dotted line; slope $=0.12, R^{2}=0.84$, Fig. $3 \mathrm{~A}$, third panel. median $=3,015$, IQR: $2,759-3,124)$ which corresponded to $80 \%$ of unique clones but only $13.3 \%$ of T-cells (IQR $=5.7-16.3 \%)$. Interestingly, a large portion of the clones identified as having a significantly greater frequency in tumor 1 than in tumor 2 (median: 90\%, IQR: $92.6-89.1 \%$ ) were also detected at low abundance in the out- 
Fractionated RT modulates the local TCR repertoire

of-field tumor. Treatment with RT and $\alpha \mathrm{PD}-1 \mathrm{mAb}$ restored some of the concordance of T-cell clones observed in the tumors of NT mice and led to greater convergence in expanded T-cell clones present in both the irradiated and out-of-field tumors (slope $=$ $\left.0.5, R^{2}=0.66\right)($ Fig. 3A, last panel and Fig. 2D). Moreover, the majority of high abundance clones in the irradiated tumor were also observed in the out-of-field tumor $($ median $=99.53 \%)$. These data demonstrate that there is a high degree of concordance in the TCR clonotypes infiltrating into both the irradiated and out-offield tumors.

Whilst RT led to an increase in the TCR repertoire overlap between the tumors, the number of clones shared between the irradiated and out-of-field tumors only increased in response to combination therapy (Fig. 3B and C). Correspondingly, few T-cell clones had higher abundance in the out-of-field tumor than in the irradiated tumor except in mice that received combined therapy (Fig. 3D). These results are consistent with T-cell trafficking either from the irradiated tumor and/or the periphery to the out-of-field tumor. Analysis of the top 25 clones identified in the irradiated tumor and tracking the frequency of these clones in the out-of-field tumor and in peripheral blood, reveals that expansion of these principal clones in the second tumor only happens following combination therapy with RT and $\alpha \mathrm{PD}-1 \mathrm{mAb}$ (Fig. 3E and Supplemental Fig. 3). Importantly, these data demonstrate that fractionated RT stimulates a polyclonal T-cell response that is restricted to the irradiated tumor site and ultimately fails to control tumor growth. When RT is delivered in combination with PD-1 blockade, this polyclonal response extends outside of the irradiated field with propagation to the out-of-field tumor and to generation of a systemic therapeutic anti-tumor response. Furthermore, dose-scheduling was critical for anti-tumor 
Fractionated RT modulates the local TCR repertoire

activity with concomitant but not sequential administration of $\alpha \mathrm{PD}-1 \mathrm{mAb}$ required to mediate tumor regressions in the non-irradiated tumor (Supplemental Fig. 4).

\section{The effects of fractionated RT rarely extend beyond the treatment site}

To provide further context to the TCR sequencing data we also characterized the changes in the tumor microenvironment by flow cytometry (experimental schema outlined in Fig. 4A). Profiling of tumor-infiltrating effector T-cells revealed that fractionated RT leads to an acute reduction in the number of $\mathrm{CD} 8^{+}$and $\mathrm{CD} 4^{+} \mathrm{T}$-cells (at day 1 and day 1 and 3 respectively) in the irradiated but not out-of-field tumors when compared to time-matched NT controls (Fig. 4B, left and middle panels). By day 7 there is a small expansion in $\mathrm{CD}^{+}$(1.47 fold compared to time-matched controls) but not $\mathrm{CD} 4^{+} \mathrm{T}$-cells in the tumor that received RT. In contrast, RT led to a significant increase in the number of $\mathrm{CD}_{11} \mathrm{~b}^{+} \mathrm{Gr}^{+}$cells infiltrating into the in-field, but not the out-of-field tumors when compared to time-matched NT controls (Fig. 4B, right panel). This change was also transient and by day 7 post RT no difference in $\mathrm{CD}_{11 \mathrm{~b}^{+}} \mathrm{Gr}^{+}$cell numbers was observed between the in- and out-of-field tumors. Given that tumor cell expression of PD-L1 may represent a biomarker of a local effector T-cell response we evaluated the impact of local RT on tumor cell PD-L1 expression both in and out of the RT field. We have previously shown that low-dose fractionated RT can lead to $\mathrm{CD} 8^{+} \mathrm{T}$-cell dependent expression of PD-L1 at an irradiated tumor site (27). Here we demonstrate that expression of PD-L1 is elevated on $\mathrm{CD}^{4} 5^{-}$tumor cells only in the irradiated, but not out-of-field lesion (at all

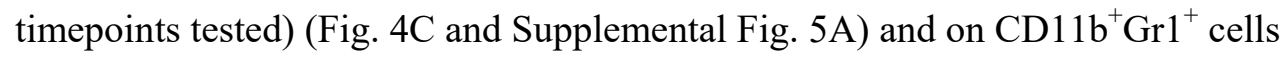
(transiently at day 3) (Fig. 4D and Supplemental Fig. 5B). We have previously demonstrated that this increase in PD-L1 following local fractionated RT is mediated 
Fractionated RT modulates the local TCR repertoire

by $\mathrm{CD} 8{ }^{+} \mathrm{T}$-cell issued IFN $\gamma(20)$. In this context, tumor cell expression of PD-L1 may be a biomarker of local effector T-cell responses suggesting that these responses are restricted to the site of treatment.

\section{Combined treatment with fractionated RT and $\alpha$ PD-1 mAb facilitates $\mathrm{CD8}^{+} \mathrm{T}-$ cell expansion in the irradiated and out-of-field tumors}

As we previously observed with RT alone, combination therapy with RT and $\alpha$ PD-1 mAb (experimental schema outlined in Fig. 5A) also led to a significant reduction in the number of $\mathrm{CD} 8^{+} \mathrm{T}$-cells (but not $\mathrm{CD} 4^{+} \mathrm{T}$-cells) infiltrating the tumor (when compared to out-of-field lesions) (Fig. 5B). However, this reduction in $\mathrm{CD}^{+}$ T-cells was acute, and by day 7 both the irradiated and out-of-field tumors had significantly greater numbers of $\mathrm{CD} 8^{+} \mathrm{T}$-cells (2.15 and 1.96 fold respectively) when compared to the time-matched NT controls. Moreover, the numbers of $\mathrm{CD} 11 \mathrm{~b}^{+} \mathrm{Gr}^{+}$ cells in the irradiated tumor were increased on day 1 post combined RT/ $\mathrm{PD}-1 \mathrm{mAb}$ therapy in the irradiated tumor when compared to the out-of-field tumor (Fig.5B). However, in contrast to our observations after RT alone, this increase was transient and followed by a significant reduction in $\mathrm{CD}_{1} 1 \mathrm{~b}^{+} \mathrm{Gr} 1^{+}$cell numbers in the irradiated tumor, when compared to the out-of-field tumor at days 3 and 7. In contrast to treatment with RT alone, combined therapy with RT and $\alpha \mathrm{PD}-1 \mathrm{mAb}$ leads to the upregulation of PD-L1 expression in both the irradiated and out-of-field tumors at all timepoints tested (Fig. 5C and Supplemental Fig. 5A). A similar pattern of PD-L1 expression was also observed on tumor infiltrating $\mathrm{CD}_{11 \mathrm{~b}^{+}} \mathrm{Gr}^{+}$cells (Fig. 5D and Supplemental Fig. 5B). Together these data demonstrate that fractionated RT, when delivered in combination with $\alpha \mathrm{PD}-1 \mathrm{mAb}$ leads to dynamic changes in tumor- 
infiltrating $\mathrm{CD}^{+}$effector T-cell populations capable of mediating regression of both irradiated and out-of-field tumors.

\section{Both tumor resident and infiltrating T-cells contribute to therapeutic activity}

\section{following combination therapy}

To determine the relative contribution of tumor resident versus infiltrating Tcells on the therapeutic response following combined RT/ $\alpha \mathrm{PD}-1 \mathrm{mAb}$ therapy we used FTY-720 (a sphingosine 1-phosphate receptor agonist) which prohibits T-cell emigration from lymphoid tissues (31). FTY-720 has been shown to have direct antitumor effects $(32,33)$. We initially confirmed that treatment with low doses of FTY720 had no effect on tumor growth whilst retaining the capacity to reduce both circulating and tumor-infiltrating T-cell populations (Supplemental Fig. 6A and B). We then determined the effect of blocking T-cell infiltration into the tumor either prior to implantation or prior to treatment (experimental schema outlined in Fig. 6A). Our data demonstrates that T-cells resident in the tumor at the time of treatment are capable of mediating therapeutic responses following combined therapy with $\sim 40 \%$ of mice that received combined $\mathrm{RT} / \alpha \mathrm{PD}-1 \mathrm{mAb}$ therapy undergoing curative responses when FTY-720 treatment was initiated on the day prior to therapy (6 days post tumor implantation) (Fig. 6B and C). However, infiltration of circulating T-cells into the tumor post therapy was required to achieve maximal responses $(\sim 80 \%$ of mice which did not receive FTY-720 achieved curative responses).

These data demonstrate that in a proportion of mice, tumor-resident T-cells have the capacity to mediate local tumor control and clearance. However, the response mediated by tumor resident T-cells appears insufficient and infiltrating $\mathrm{T}$ - 
Fractionated RT modulates the local TCR repertoire

cells from outside of tumor are also required for successful clearance of tumor in the majority of mice following combination RT/ $\alpha \mathrm{PD}-1 \mathrm{mAb}$ therapy.

\section{Discussion}

In this study we demonstrate for the first time that low-dose daily fractionated RT leads to polyclonal T-cell infiltration and expansion at the site of treatment but that the generation of systemic anti-tumor immunity is suppressed through the PD1/PD-L1 axis. Inhibition of this axis facilitated the generation of a systemic polyclonal T-cell response capable of mediating out-of-field (abscopal) effects following local RT. Our data demonstrate that both tumor-resident and infiltrating Tcells contribute to tumor control following combined therapy. Furthermore, immunosequencing of the CDR3 regions of TCR $\beta$ revealed that all of the dominant Tcell clones were present in both the irradiated and out-of-field tumors.

We have previously demonstrated that fractionated RT leads to local T-cell activation and production of IFN $\gamma$ which drives adaptive resistance through the PD1/PD-L1 axis (20). In this study we provide additional insight into this T-cell response and demonstrate that low-dose daily fractionated RT modulates the TCR repertoire leading to polyclonal expansion of pre-existing TIL populations within the irradiated tumor but not within the out-of-field non-irradiated tumor, co-incident with the emergence of immunological suppression. Here we show that RT leads to increases in PD-L1 expression on both tumor cells and $\mathrm{CD} 11 \mathrm{~b}^{+} \mathrm{Gr} 1^{+}$cells only within the irradiated tumor. Given that PD-L1 expression in the tumor microenvironment appears to be a biomarker for local $\mathrm{CD} 8^{+} \mathrm{T}$-cell activation this data suggests that the immune response is restricted to the site of RT. Complete regression of both the 
Fractionated RT modulates the local TCR repertoire

irradiated and out-of-field tumors following treatment with fractionated RT alone was a rare event across independent experiments and it remains unclear what local and systemic events underpin these responses. In contrast, concurrent treatment with RT and $\alpha \mathrm{PD}-1 \mathrm{mAb}$ overcomes this local immunosuppression facilitating systemic antitumor immunity capable of mediating the regression of distal, non-irradiated lesions which also exhibit increased expression of PD-L1 on tumor and $\mathrm{CD} 11 \mathrm{~b}^{+} \mathrm{Gr} 1^{+}$cells. Sequential therapy where PD-1 blockade began 7 days after completion of the fractionated RT cycle was ineffective suggesting that whilst fractionated RT can lead to changes in the TCR repertoire in the irradiated tumor, exhaustion and subsequent atrophy of tumor-reactive TILs may occur rapidly after RT unless signaling through the PD-1/PD-L1 axis is blocked. Whilst regression of irradiated tumor has previously been shown to be $\mathrm{CD} 8^{+} \mathrm{T}$-cell dependent (27) further mechanistic studies would be required to determine the relative contribution of the distinct T-cell clones at the irradiated and out-of-field tumor sites and confirm causality to response.

The frequency of T-cells in the tumor is well documented to predict outcome (34); however, the relative contribution of tumor resident versus infiltrating T-cells on therapeutic response following combination RT and $\alpha \mathrm{PD}-1 \mathrm{mAb}$ therapy are unclear. The analysis of the TCR repertoires in the blood and tumor demonstrate that fractionated RT leads to T-cell infiltration in the irradiated tumor but not the distal non-irradiated tumor site. However, whilst both tumor resident and infiltrating T-cells were required for complete responses in approximately $80 \%$ of mice following combined therapy, a proportion of mice elicited complete tumor regressions mediated by resident T-cells alone. This is despite the radiosensitivity of lymphocytes and subsequent observed reduction in TIL number within 24 hours after a fractionated RT cycle. Furthermore, by day 7 post combination therapy both the irradiated and out-of- 
Fractionated RT modulates the local TCR repertoire

field tumors had significantly greater numbers of $\mathrm{CD} 8^{+} \mathrm{T}$-cells after daily fractionated RT. Although it cannot be ruled out that T-cell numbers increased due to shrinkage of the tumour this data suggests that those T-cells which are activated following RT may be more radioresistant, potentially through modulation of anti-apoptotic proteins such as BCL-2, BCL-xl and Bim (35). However, maximal therapeutic responses required both resident and infiltrating T-cells. Preclinical studies demonstrate that naïve TILs can undergo activation and differentiation within the tumor microenvironment in the presence of sufficient antigen and co-stimulation provided by local APC $(36,37)$. Given the immunogenic nature of RT, further studies are required to delineate the relative contribution of in situ priming by tumor resident APC versus classical priming in secondary lymphoid organs.

The generation of neo-antigens secondary to DNA-damage following ionizing radiation is hypothesized to contribute to tumor control through broadening of the TCR repertoire (4). Our data suggests that following fractionated RT only a small fraction of T-cells $(<0.5 \%)$ are unique to the irradiated tumor, and therefore we speculate may be specific for a neo-antigen generated by RT. In addition, the high level of concordance in the high-abundance clones present in both the irradiated and out of field tumor suggest that the antigens may be shared across the 2 tumors. These data suggest that following low-dose fractionated therapy the T-cell response may be dominated by clones responding to pre-existing tumor antigens and we speculate that the response against potential neo-antigens generated as a consequence of RT-induced DNA-damage may be minimal. Interestingly, the addition of $\alpha \mathrm{PD}-1 \mathrm{mAb}$ to RT does not significantly alter the clonality or diversity of the T-cell repertoire above that of RT alone. Presumably this is because inhibition of signaling through PD-1 may principally operate to reinvigorate T-cells. However, NGS of TCRs does not enable 
Fractionated RT modulates the local TCR repertoire

identification of specific peptide antigens or define the lineage of the TCR expressing cell and further mechanistic studies would need to be undertaken to confirm the specificity of TCR clonotypes restricted to $\mathrm{CD}^{+}$and $\mathrm{CD} 8^{+} \mathrm{T}$-cells. Moreover, targeting co-activatory immune checkpoints such as CTLA-4 have been shown to broaden the peripheral TCR repertoire $(38,39)$. Therefore, combining RT and aCTLA-4 mAb may co-operate to further enhance repertoire diversity and potentially improve therapeutic outcome $(22,25)$.

Recent advances in the delivery of RT such as stereotactic ablative radiation therapy (SBRT) permit high single-fraction doses to be administered to patients with minimal collateral damage to normal tissue. Preclinical evidence across a range of syngeneic models demonstrates that RT dose fractionation can influence systemic immune response and subsequent tumor control $(23,27,40,41)$. A number of recent publications have demonstrated the enhancement of anti-tumor immune responses when mAbs targeting co-inhibitory/activatory receptors such as PD-1/PD-L1, CTLA4 and CD137 are combined with high ablative single (e.g. 10 / 12 Gy (42), 12 Gy $(19,24)$ or 20 Gy $(25))$ or hypofractionated RT-regimens (e.g. 3 x 8 Gy $(21,23)$ or 5 x 6 Gy (22)). Moreover, increased TCR diversity in irradiated tumors was also described in a preclinical model following treatment with a single dose of 20 Gy RT (25). Despite our data in the CT26 model demonstrating that varying RT dose fractionation has little effect on therapeutic response when combined with blockade of the PD-1/PD-L1 pathway, the extent to which these different RT dose and fractionation approaches may differently modulate neo-antigen generation, TCR diversity and therapeutic response in the clinical setting remains unclear and requires further investigation. The impact of RT delivered as low-dose fractionated regimens, higher dose hypofractionated and single-dose ablative RT is not only likely to effect 
Fractionated RT modulates the local TCR repertoire

the amount, kinetics and type of tumor cell death it is also likely to be affected by the intrinsic radiosensitivity and microenvironment of the tumor. Higher RT doses are more likely to have very different effects on the tumor microenvironment and antitumor immune response compared to the lower 2 Gy per day fractionated RT which was used in this study and routinely given to a majority of cancer patients. The effect of RT dose and fractionation has been shown in a recent study demonstrating that a single 30 Gy dose of RT stimulated curative $\mathrm{CD} 8^{+} \mathrm{T}$-cell dependent responses but that this effect was abrogated when followed by 10 days of fractionated therapy ( 3 Gy / day) (41). These data suggest that that repeated doses of RT to the tumor may be detrimental to the anti-tumor immune response and this may have profound implications for the current practice of irradiating tumor draining lymph nodes, which needs further study.

A number of clinical trials are currently on-going to further delineate optimum RT dose and fractionation schedules to improve immunologic response (43). Whilst RT alone has been shown to induce abscopal effects in a limited number of patients (44) reports of abscopal effects following concurrent RT and immunotherapy are currently limited to case reports and results from clinical trials investigating RT plus immune checkpoint blockade are eagerly awaited. In conclusion, the combination of RT and immunotherapy holds great promise to improve cancer outcomes. Unlocking this potential requires further investigation with well-designed clinical trials investigating the effect of RT dose fractionation in different tumors to guide the next phases of clinical development.

Acknowledgments: Funding: Research was supported by a grant from MedImmune and Cancer Research UK (A17737). Author contributions: S.J.D., conceived and conducted the research, analyzed and interpreted the data and wrote the manuscript. R.W.W., J.H., and T.M.I., also contributed to conception of the research, 
Fractionated RT modulates the local TCR repertoire

interpretation of data and editing of the manuscript. E.J.C., E.P., M.M., R.S., R.W.W. R.O. E., C.S., E.Y., and M.V. H.R. analyzed and interpreted the data, and edited the manuscript.

\section{References}

1. Verellen D, De Ridder M, Linthout N, Tournel K, Soete G, Storme G. Innovations in image-guided radiotherapy. Nat Rev Cancer 2007;7:949-60

2. Lee LJ, Harris JR. Innovations in radiation therapy (RT) for breast cancer. Breast 2009;18 Suppl 3:S103-11

3. Kapiteijn E, Marijnen CA, Nagtegaal ID, Putter H, Steup WH, Wiggers T, et al. Preoperative radiotherapy combined with total mesorectal excision for resectable rectal cancer. N Engl J Med 2001;345:638-46

4. Reits EA, Hodge JW, Herberts CA, Groothuis TA, Chakraborty M, Wansley EK, et al. Radiation modulates the peptide repertoire, enhances MHC class I expression, and induces successful antitumor immunotherapy. The Journal of experimental medicine 2006;203:1259-71

5. Burnette BC, Liang H, Lee Y, Chlewicki L, Khodarev NN, Weichselbaum RR, et al. The efficacy of radiotherapy relies upon induction of type i interferondependent innate and adaptive immunity. Cancer research 2011;71:2488-96

6. Sistigu A, Yamazaki T, Vacchelli E, Chaba K, Enot DP, Adam J, et al. Cancer cell-autonomous contribution of type I interferon signaling to the efficacy of chemotherapy. Nat Med 2014;20:1301-9

7. Deng L, Liang H, Xu M, Yang X, Burnette B, Arina A, et al. STINGDependent Cytosolic DNA Sensing Promotes Radiation-Induced Type I Interferon-Dependent Antitumor Immunity in Immunogenic Tumors. Immunity 2014;41:843-52

8. Surace L, Lysenko V, Fontana AO, Cecconi V, Janssen H, Bicvic A, et al. Complement is a central mediator of radiotherapy-induced tumor-specific immunity and clinical response. Immunity 2015;42:767-77

9. Kroemer G, Galluzzi L, Kepp O, Zitvogel L. Immunogenic cell death in cancer therapy. Annu Rev Immunol 2013;31:51-72

10. Spary LK, Al-Taei S, Salimu J, Cook AD, Ager A, Watson HA, et al. Enhancement of $\mathrm{T}$ cell responses as a result of synergy between lower doses of radiation and T cell stimulation. Journal of immunology 2014;192:3101-10

11. Apetoh L, Ghiringhelli F, Tesniere A, Obeid M, Ortiz C, Criollo A, et al. Tolllike receptor 4-dependent contribution of the immune system to anticancer chemotherapy and radiotherapy. Nat Med 2007;13:1050-9

12. Gardai SJ, McPhillips KA, Frasch SC, Janssen WJ, Starefeldt A, MurphyUllrich JE, et al. Cell-surface calreticulin initiates clearance of viable or apoptotic cells through trans-activation of LRP on the phagocyte. Cell 2005; $123: 321-34$

13. Ghiringhelli F, Apetoh L, Tesniere A, Aymeric L, Ma Y, Ortiz C, et al. Activation of the NLRP3 inflammasome in dendritic cells induces IL-1betadependent adaptive immunity against tumors. Nat Med 2009;15:1170-8

14. Ma Y, Adjemian S, Mattarollo SR, Yamazaki T, Aymeric L, Yang H, et al. Anticancer chemotherapy-induced intratumoral recruitment and differentiation of antigen-presenting cells. Immunity 2013;38:729-41 
Fractionated RT modulates the local TCR repertoire

15. Cummings B, Keane T, Pintilie M, Warde P, Waldron J, Payne D, et al. Five year results of a randomized trial comparing hyperfractionated to conventional radiotherapy over four weeks in locally advanced head and neck cancer. Radiother Oncol 2007;85:7-16

16. Dong H, Strome SE, Salomao DR, Tamura H, Hirano F, Flies DB, et al. Tumor-associated B7-H1 promotes T-cell apoptosis: a potential mechanism of immune evasion. Nat Med 2002;8:793-800

17. Freeman GJ, Long AJ, Iwai Y, Bourque K, Chernova T, Nishimura H, et al. Engagement of the PD-1 immunoinhibitory receptor by a novel B7 family member leads to negative regulation of lymphocyte activation. The Journal of experimental medicine 2000; 192:1027-34

18. Patsoukis N, Bardhan K, Chatterjee P, Sari D, Liu B, Bell LN, et al. PD-1 alters T-cell metabolic reprogramming by inhibiting glycolysis and promoting lipolysis and fatty acid oxidation. Nature communications 2015;6:6692

19. Deng L, Liang H, Burnette B, Beckett M, Darga T, Weichselbaum RR, et al. Irradiation and anti-PD-L1 treatment synergistically promote antitumor immunity in mice. J Clin Invest 2014;124:687-95

20. Dovedi SJ, Adlard AL, Lipowska-Bhalla G, McKenna C, Jones S, Cheadle EJ, et al. Acquired resistance to fractionated radiotherapy can be overcome by concurrent PD-L1 blockade. Cancer research 2014;74:5458-68

21. Rodriguez-Ruiz ME, Rodriguez I, Garasa S, Barbes B, Solorzano JL, PerezGracia JL, et al. Abscopal Effects of Radiotherapy Are Enhanced by Combined Immunostimulatory mAbs and Are Dependent on CD8 T Cells and Crosspriming. Cancer research 2016;76:5994-6005

22. Demaria S, Kawashima N, Yang AM, Devitt ML, Babb JS, Allison JP, et al. Immune-mediated inhibition of metastases after treatment with local radiation and CTLA-4 blockade in a mouse model of breast cancer. Clin Cancer Res 2005; $11: 728-34$

23. Dewan MZ, Galloway AE, Kawashima N, Dewyngaert JK, Babb JS, Formenti $\mathrm{SC}$, et al. Fractionated but not single-dose radiotherapy induces an immunemediated abscopal effect when combined with anti-CTLA-4 antibody. Clin Cancer Res 2009; $15: 5379-88$

24. Sharabi AB, Nirschl CJ, Kochel CM, Nirschl TR, Francica BJ, Velarde E, et al. Stereotactic Radiation Therapy Augments Antigen-Specific PD-1Mediated Antitumor Immune Responses via Cross-Presentation of Tumor Antigen. Cancer immunology research 2015;3:345-55

25. Twyman-Saint Victor C, Rech AJ, Maity A, Rengan R, Pauken KE, Stelekati $\mathrm{E}$, et al. Radiation and dual checkpoint blockade activate non-redundant immune mechanisms in cancer. Nature 2015;520:373-7

26. Spranger S, Spaapen RM, Zha Y, Williams J, Meng Y, Ha TT, et al. Upregulation of $\mathrm{PD}-\mathrm{L} 1$, IDO, and T(regs) in the melanoma tumor microenvironment is driven by CD8(+) T cells. Sci Transl Med 2013;5:200ra116

27. Dovedi SJ, Melis MH, Wilkinson RW, Adlard AL, Stratford IJ, Honeychurch $\mathrm{J}$, et al. Systemic delivery of a TLR7 agonist in combination with radiation primes durable antitumor immune responses in mouse models of lymphoma. Blood 2013;121:251-9

28. Carlson CS, Emerson RO, Sherwood AM, Desmarais C, Chung MW, Parsons $\mathrm{JM}$, et al. Using synthetic templates to design an unbiased multiplex PCR assay. Nat Commun 2013;4:2680 
29. Robins HS, Campregher PV, Srivastava SK, Wacher A, Turtle CJ, Kahsai O, et al. Comprehensive assessment of T-cell receptor beta-chain diversity in alphabeta T cells. Blood 2009; 114:4099-107

30. DeWitt WS, Emerson RO, Lindau P, Vignali M, Snyder TM, Desmarais C, et al. Dynamics of the cytotoxic T cell response to a model of acute viral infection. J Virol 2015;89:4517-26

31. Zhi L, Kim P, Thompson BD, Pitsillides C, Bankovich AJ, Yun SH, et al. FTY720 blocks egress of T cells in part by abrogation of their adhesion on the lymph node sinus. Journal of immunology 2011;187:2244-51

32. LaMontagne K, Littlewood-Evans A, Schnell C, O'Reilly T, Wyder L, Sanchez T, et al. Antagonism of Sphingosine-1-Phosphate Receptors by FTY720 Inhibits Angiogenesis and Tumor Vascularization. Cancer research 2006; $66: 221-31$

33. Lee TK, Man K, Ho JW, Wang XH, Poon RTP, Xu Y, et al. FTY720: A Promising Agent for Treatment of Metastatic Hepatocellular Carcinoma. Clinical Cancer Research 2005;11:8458-66

34. Galon J, Costes A, Sanchez-Cabo F, Kirilovsky A, Mlecnik B, Lagorce-Pages $\mathrm{C}$, et al. Type, density, and location of immune cells within human colorectal tumors predict clinical outcome. Science 2006;313:1960-4

35. Koenen P, Heinzel S, Carrington EM, Happo L, Alexander WS, Zhang JG, et al. Mutually exclusive regulation of T cell survival by IL-7R and antigen receptor-induced signals. Nature communications 2013;4:1735

36. Thompson ED, Enriquez HL, Fu YX, Engelhard VH. Tumor masses support naive $\mathrm{T}$ cell infiltration, activation, and differentiation into effectors. J Exp Med 2010;207:1791-804

37. Yu P, Lee Y, Liu W, Chin RK, Wang J, Wang Y, et al. Priming of naive T cells inside tumors leads to eradication of established tumors. Nature immunology 2004;5:141-9

38. Robert L, Harview C, Emerson R, Wang X, Mok S, Homet B, et al. Distinct immunological mechanisms of CTLA-4 and PD-1 blockade revealed by analyzing TCR usage in blood lymphocytes. Oncoimmunology 2014;3:e29244

39. Cha E, Klinger M, Hou Y, Cummings C, Ribas A, Faham M, et al. Improved survival with $\mathrm{T}$ cell clonotype stability after anti-CTLA-4 treatment in cancer patients. Sci Transl Med 2014;6:238ra70

40. Lugade AA, Moran JP, Gerber SA, Rose RC, Frelinger JG, Lord EM. Local radiation therapy of B16 melanoma tumors increases the generation of tumor antigen-specific effector cells that traffic to the tumor. Journal of immunology 2005; $174: 7516-23$

41. Filatenkov A, Baker J, Mueller AM, Kenkel J, Ahn GO, Dutt S, et al. Ablative Tumor Radiation Can Change the Tumor Immune Cell Microenvironment to Induce Durable Complete Remissions. Clin Cancer Res 2015;21:3727-39

42. Zeng J, See AP, Phallen J, Jackson CM, Belcaid Z, Ruzevick J, et al. Anti-PD1 blockade and stereotactic radiation produce long-term survival in mice with intracranial gliomas. International journal of radiation oncology, biology, physics 2013;86:343-9

43. Crittenden MR, Savage T, Cottam B, Baird J, Rodriguez PC, Newell P, et al. Expression of arginase I in myeloid cells limits control of residual disease after radiation therapy of tumors in mice. Radiation research 2014;182:182-90 
Fractionated RT modulates the local TCR repertoire

44. Reynders K, Illidge T, Siva S, Chang JY, De Ruysscher D. The abscopal effect of local radiotherapy: using immunotherapy to make a rare event clinically relevant. Cancer treatment reviews 2015;41:503-10

\section{Figure Legends}

Figure 1. Combination of fractionated RT and blockade of the PD-1/PD-L1 axis leads to improved survival and generation of tumor-specific memory immune

responses. (A and B) CT26 (A) or 4434 (B) tumor bearing mice received fractionated RT delivered in 5 daily fractions of 2 Gy either in combination with either $\alpha \mathrm{PD}$ 1/aPD-L1 mAb dosed at $10 \mathrm{mg} / \mathrm{kg} 3 \mathrm{qw}$. Treatments started 7 days after tumor inoculation. Experimental groups contained at least 7 mice, except NT and RT groups which contained 14 mice. Data representative of 2 independent experiments. (C) Survival curve of long-term surviving (LTS) mice originally treated with RT and $\alpha \mathrm{PD}-1 \mathrm{mAb} / \alpha \mathrm{PD}-\mathrm{L} 1 \mathrm{mAb}$ following rechallenge with $5 \times 10^{5} \mathrm{CT} 26$ cells.

Experimental groups contained at least 4 mice. (D) Frequency of IFN $\gamma^{+} \mathrm{CD} 8^{+} \mathrm{T}$-cells isolated from either tumor naïve, or LTS mice originally treated with RT and $\alpha \mathrm{PD}-\mathrm{L} 1$ mAb following co-culture with either H2-Ld restricted peptides (AH1 (SPSYVYHQF); a defined CT26 tumor-associated antigen or $\beta$-galactosidase (TPHPARIGL); control peptide of prokaryotic origin) or 50 Gy irradiated CT26 cells for 5 days, followed by priming with 50 Gy irradiated CT26 cells. Experimental groups contained at least 4 mice, and the data shown are representative of at least 2 independent experiments. (E) CT26 tumor bearing mice received either 7 Gy or 3 daily fractions of 4 Gy alone or in combination with an $\alpha \mathrm{PD}-1 \mathrm{mAb}$ dosed at 10 $\mathrm{mg} / \mathrm{kg} 3 \mathrm{qw}$. The proportion of mice that experienced complete tumor resolution is indicated in each panel. $\mathrm{C},{ }^{* *}, \mathrm{P}<0.01,+, \mathrm{P}<0.05$, Log-rank (Mantel-Cox) test. D, shows mean \pm SEM. * $\mathrm{P}<0.05$, Mann-Whitney test. 
Fractionated RT modulates the local TCR repertoire

Figure 2. RT leads to local T-cell infiltration/expansion and broadening of the TCR repertoire but systemic responses are only observed when combined with

aPD-1 mAb. (A) Schema for studies. Fractionated-dose RT (as 10 Gy in 5 daily fractions of 2 Gy) was delivered to tumor 1 with tumor 2 shielded from the ionising beam in combination with $\alpha \mathrm{PD}-1 \mathrm{mAb}$ dosed at $10 \mathrm{mg} / \mathrm{kg}$ 3qw for 1 week. (B), Individual tumor growth curves. The proportion of mice that experienced complete tumor resolution is indicated in each panel. Experimental groups contained at least 4 mice, and the data shown are representative of at least 3 independent experiments (for $\alpha \mathrm{PD}-1 \mathrm{mAb}$ only arms these data comprise a minimum of 5 mice and 2 independent experiments). (C-F) Cohorts of 5 mice per group were euthanized 7 days after the last dose of RT and TCR metrics determined. (C), T-cell infiltration/expansion. (D), the number of TCR molecules detected in post-therapy blood samples and the respective tumor sample divided by the total number of TCR molecules in the two samples. (E), TCR clonality. (F), number of unique TCRs identified in both tumors stratified by therapy. Asterisks with bars indicate pair-wise comparisons between the tumors within a therapy group **, ${ }^{*}<0.01, *, \mathrm{P}<0.05$ - paired t-test, and stand-alone asterisks denotes significance when compared to NT control **, P $<0.01$, or *, $\mathrm{P}<0.05$ level.

Figure 3. Combination therapy leads to convergence of the TCR repertoires in both irradiated and out-of-field tumors. (A), scatterplots of clone abundance in tumor 2 versus tumor 1 following treatment. Points to the left of or below the dotted line were TCR clones detected in only tumor 2 or tumor 1, respectively. Quantitation of overlap metrics between the TCR repertoires of tumor 2 and tumor 1 are: (B), the number of shared TCR molecules identified in sequencing divided by the total 
Fractionated RT modulates the local TCR repertoire

number of TCR molecules in the two samples, (C), number of unique TCR clones that were found in both tumors, and (D), the number of clones with significantly greater frequency in tumor 2 than in tumor 1. (E), the top 25 clones in tumor 1 were tracked in pre-therapy blood, post-therapy blood, and in post-therapy tumor 2 samples; the plots quantify the T-cell fraction (T-cells per nucleated cell) for each clone in each sample. Each graph is representative of an individual animal. Asterisks with bars indicate pair-wise comparisons between the tumors within a therapy group: ${ }^{* * *}, \mathrm{P}<$ $0.001,{ }^{* *}, P<0.01,{ }^{*}, P<0.05$ - paired t-test. Experimental groups contained 5 mice.

Figure 4. Fractionated RT leads to transient depletion of $T$ cells and expansion of $\mathrm{CD11b}^{+} \mathrm{Gr1}^{+}$cells at the site of treatment. (A) Schema for studies. Fractionateddose RT (as 10 Gy in 5 daily fractions of 2 Gy) was delivered to tumor 1 with tumor 2 shielded from the ionising beam. (B) Fold change in $\mathrm{CD} 8^{+}$(left panel), $\mathrm{CD} 4^{+}$(middle panel) and $\mathrm{CD} 1 \mathrm{bb}^{+} \mathrm{Gr} 1^{+}$(right panel) cells compared to non-treated time-matched controls in the irradiated (1) and out-of-field (2) tumors. (C and D) Expression of PD$\mathrm{L} 1$ on $\mathrm{CT} 26$ cells $\left(\mathrm{C}\right.$, gated as $\mathrm{CD}^{-} 5^{-}$cells) and on $\mathrm{CD} 45^{+} \mathrm{CD} 11 \mathrm{~b}^{+} \mathrm{Gr} 1^{+}$(D) 24 hours, 72 hours and 7 days post treatment with 5 fractions of 2 Gy RT. Fold changes were calculated by determining the frequency of cells as a population of $\mathrm{CD} 45^{+}$and then expressing these relative to their frequency in time/anatomical implant site-matched NT control mice. Dashed line represents the baseline for each tumor implanted in mice receiving NT. ${ }^{* * *}, P<0.001,{ }^{* *}, P<0.01,{ }^{*}, P<0.05$ (Mann-Whitney test). Experimental groups contained 4-5 mice, and the data shown are representative of at least 2 independent experiments. 
Fractionated RT modulates the local TCR repertoire

Figure 5. Fractionated RT delivered concurrently with $\alpha$ PD-1 mAb leads to adaptive immunological changes in both irradiated and out-of-field tumors and systemic tumor control. (A) Schema for studies. Fractionated-dose RT (as 10 Gy in 5 daily fractions of 2 Gy) was delivered to tumor 1 with tumor 2 shielded from the ionising beam in combination with $\alpha$ PD-1 mAb dosed at $10 \mathrm{mg} / \mathrm{kg}$ 3qw for 1 week.

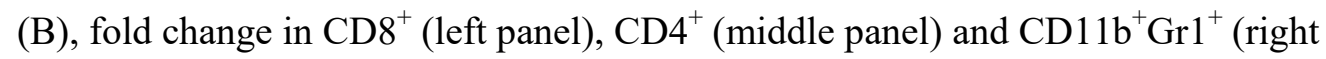
panel) cells compared to non-treated time-matched controls in the irradiated (1) and shielded (2) tumors. Fold changes were calculated by determining the frequency of cells as a population of $\mathrm{CD}_{4} 5^{+}$and then expressing these relative to their frequency in time/anatomical implant site-matched NT control mice. Dashed line represents the baseline for each tumor implanted in mice receiving NT. (C and D) Expression of PDL1 on CT26 cells (C, gated as CD45 cells) and on $\mathrm{CD}^{-} 5^{+} \mathrm{CD} 11 \mathrm{~b}^{+} \mathrm{Gr} 1^{+}$(D) 24 hours, 72 hours and 7 days post treatment. ${ }^{* * *}, P<0.001,{ }^{* *}, P<0.01,{ }^{*}, P<0.05$ (MannWhitney test). Experimental groups contained 3-5 mice, and the data shown are representative of at least 2 independent experiments.

Figure 6. Tumor resident and infiltrating T-cells contribute to the therapeutic response following fractionated $\mathrm{RT}$ and blockade and $\alpha \mathrm{PD}-1 \mathrm{mAb}$ therapy. (A), Schema for studies. CT26 tumor bearing mice received fractionated RT delivered in 5 daily fractions of $2 \mathrm{~Gy}$ in combination with $\alpha \mathrm{PD}-1 \mathrm{mAb}$ dosed at $10 \mathrm{mg} / \mathrm{kg}$ 3qw for 1 week. Cohorts of mice also received FTY-720 dosed at $25 \mu \mathrm{g} /$ mouse for the first dose and $5 \mu \mathrm{g} /$ mouse qd for up to 6 weeks. (B) Individual tumor growth curves. Pie charts represent the proportion of mice that experienced complete tumor resolution. (C), Kaplan Meier curves of therapy. Experimental groups contained at least 7 mice, and 
Author Manuscript Published OnlineFirst on May 22, 2017; DOI: 10.1158/1078-0432.CCR-16-1673

Author manuscripts have been peer reviewed and accepted for publication but have not yet been edited.

Fractionated RT modulates the local TCR repertoire

the data shown are representative of at least 2 independent experiments. $\mathrm{n} / \mathrm{s}, \mathrm{P}>0.05$,

Mann-Whitney test. ${ }^{* * *}, P<0.001$, Log-rank (Mantel-Cox) test. Research. 
s.c. implantation of

tumor Day 1

5 fractions of 2 Gy RT

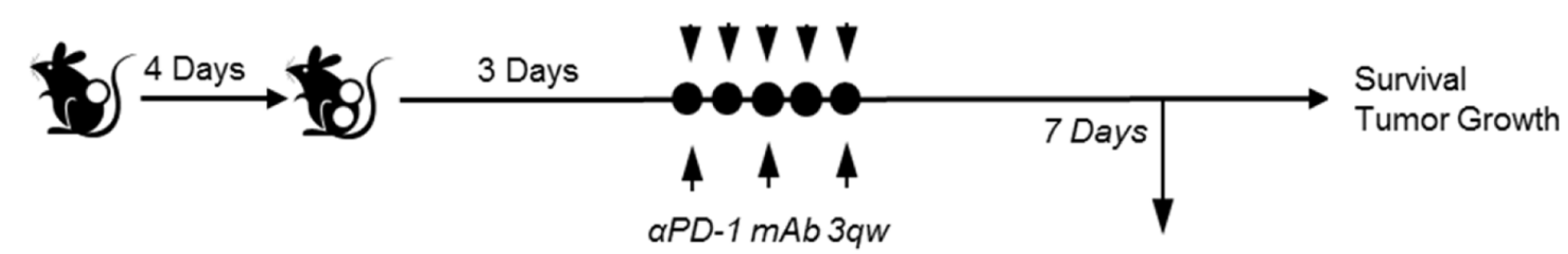

for 1 week

NGS of the TCR repertoire

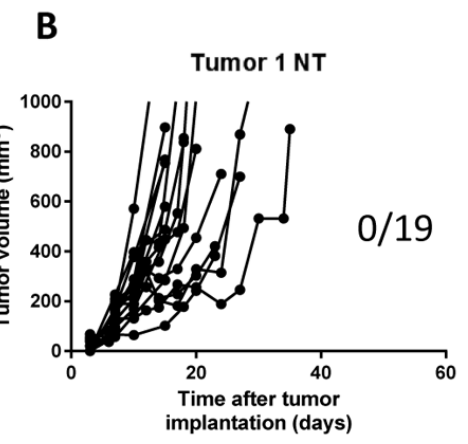

Tumor 2 NT

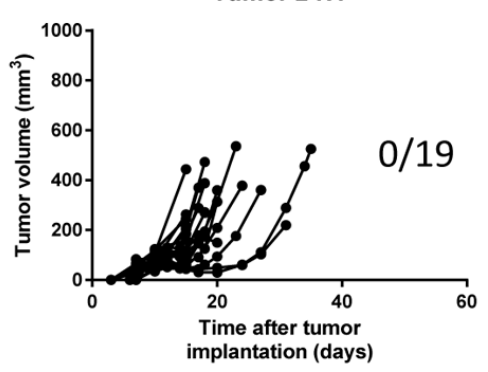

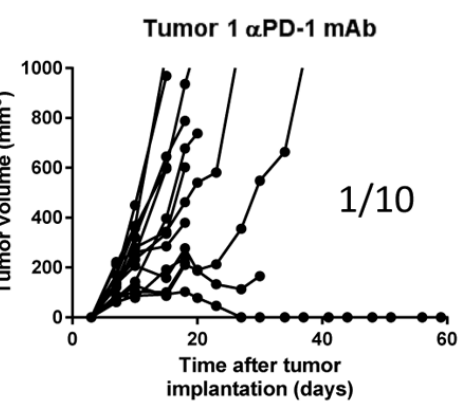

Tumor $2 \alpha$ PD-1 mAb

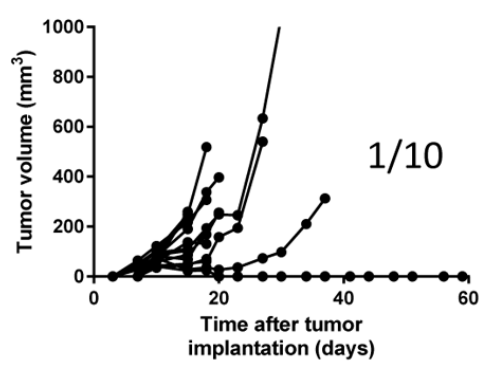

Tumor 1 RT (in IR field)

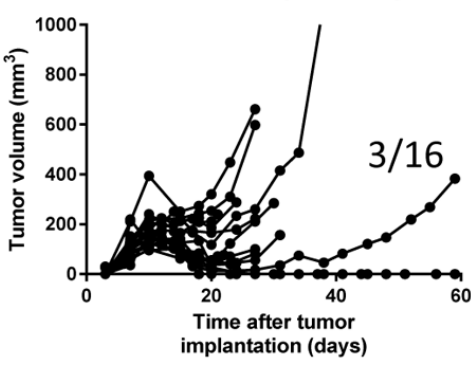

Tumor 2 RT (out of IR field)

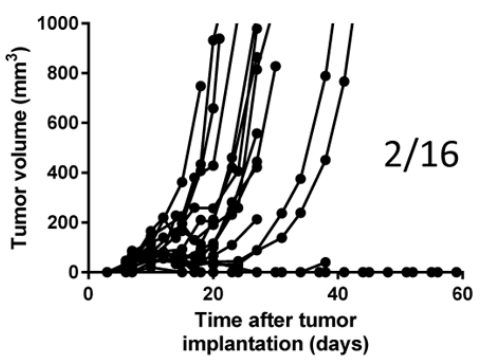

Tumor $1 \mathbf{R T}$ (in IR field) $+\alpha$ PD-1 mAb

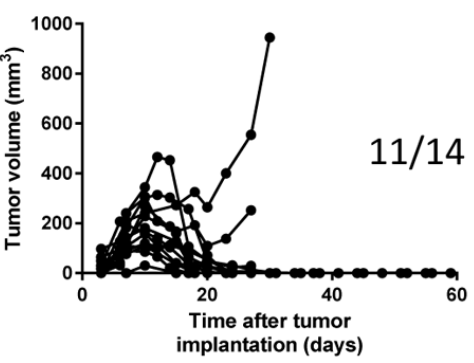

Tumor 2 RT (out of IR field) $+\alpha$ PD-1 mAb

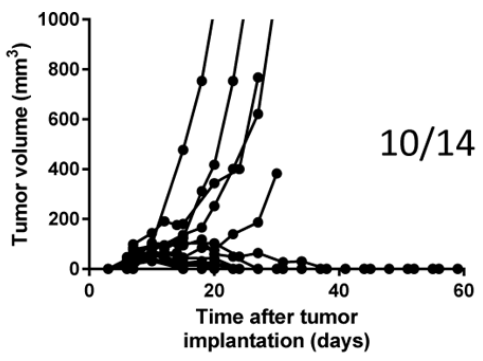

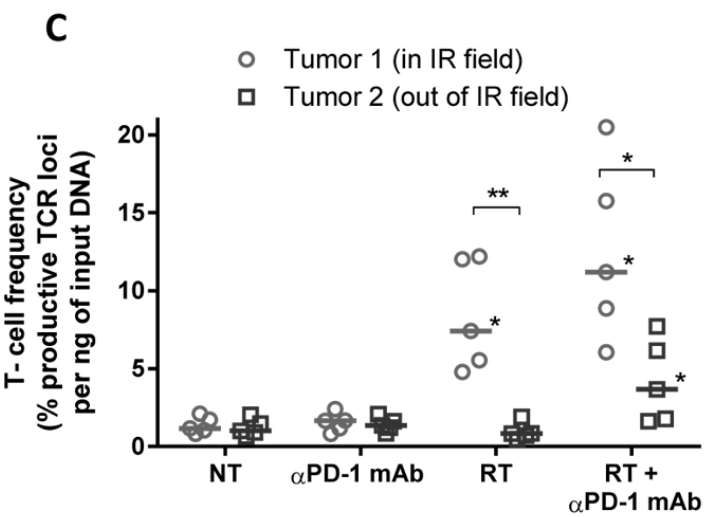

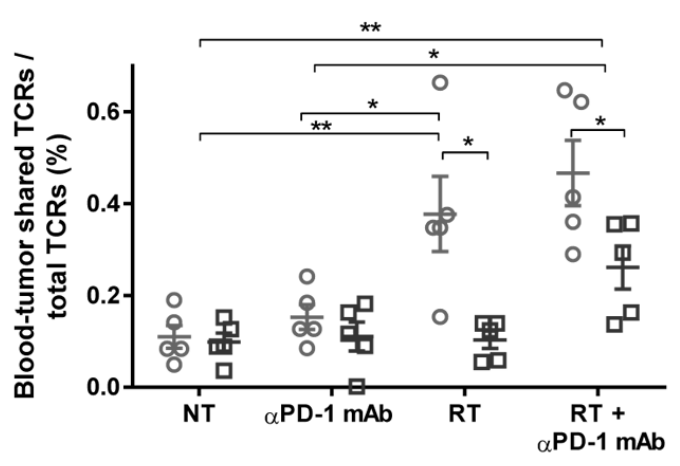

E

$\mathbf{F}$

- Tumor 1 (in IR field)

ㅁ Tumor 2 (out of IR field)
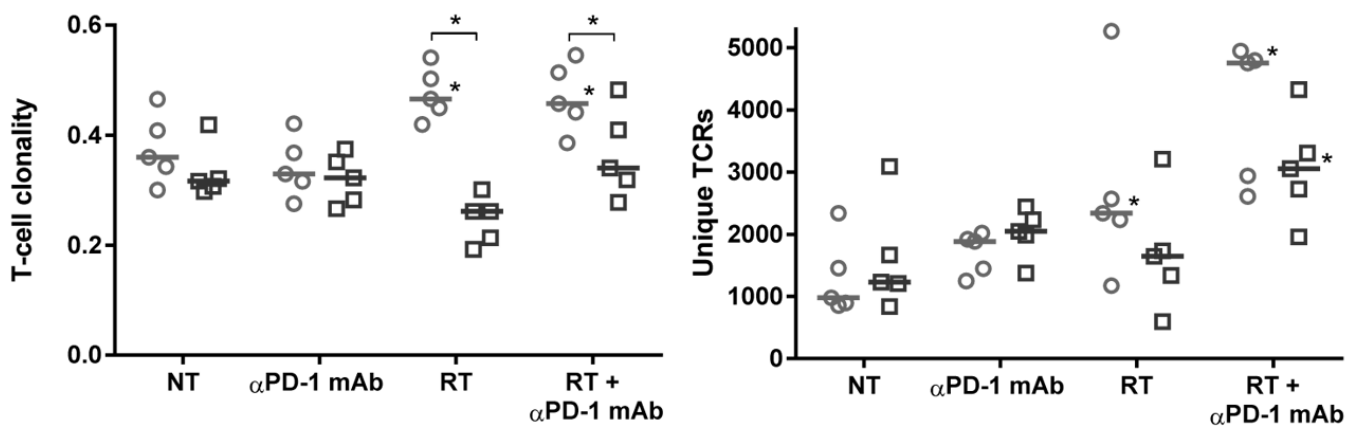

Downloaded from clincancerres.aacrjournals.org on June 1, 2017. (C) 2017 American Association for Cancer 
A

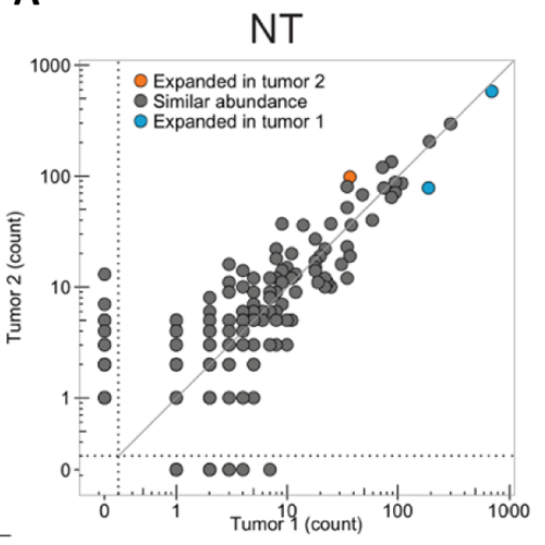

B
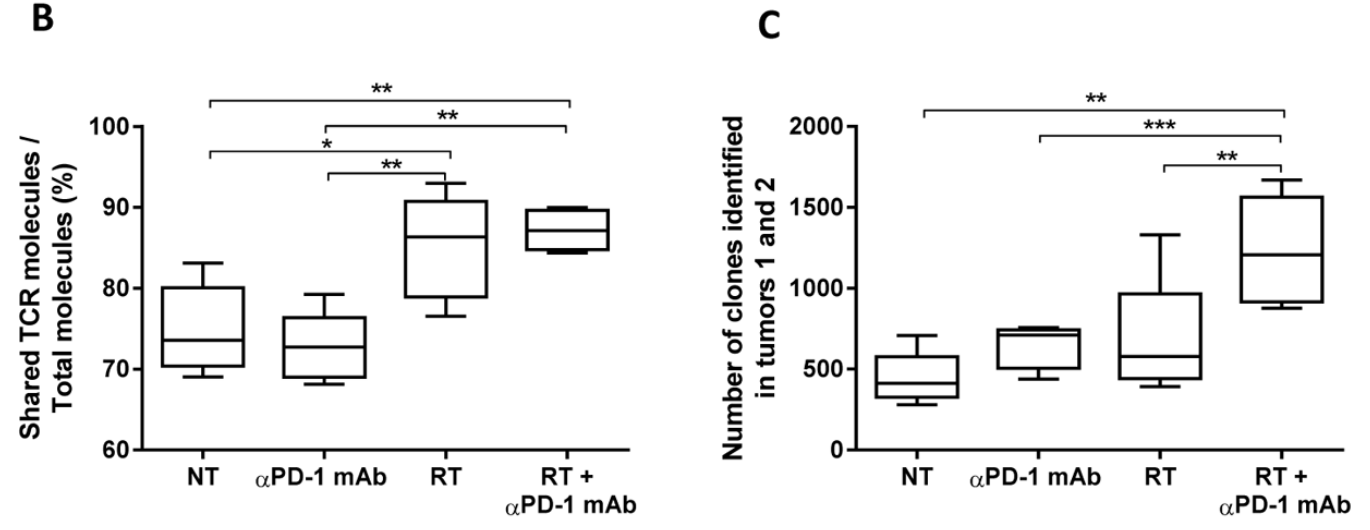

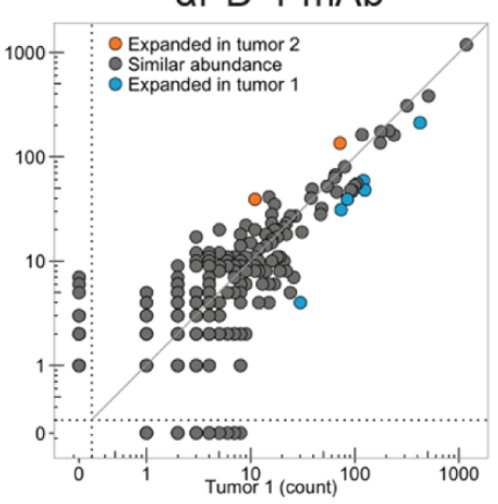

RT

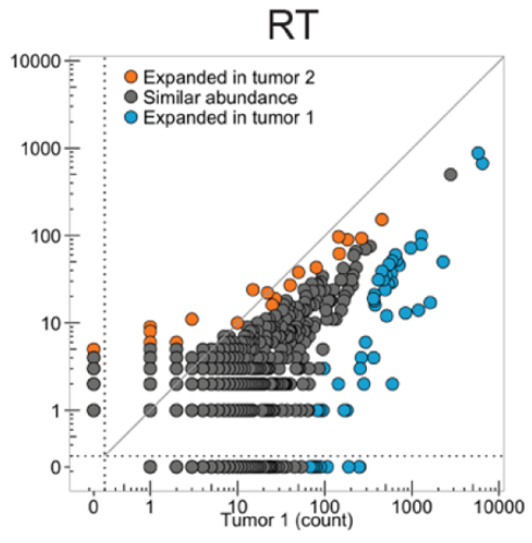

$\mathrm{RT}+\mathrm{aPD}-1 \mathrm{mAb}$

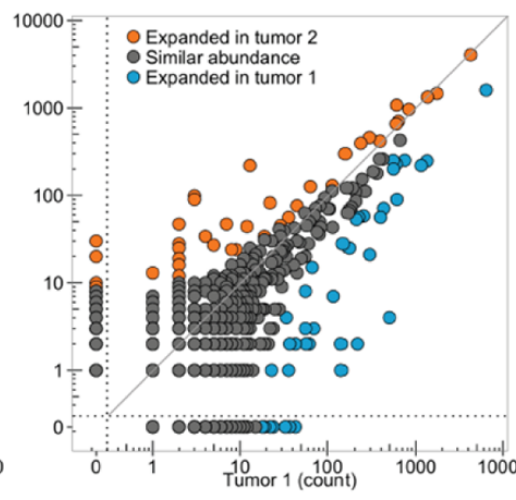

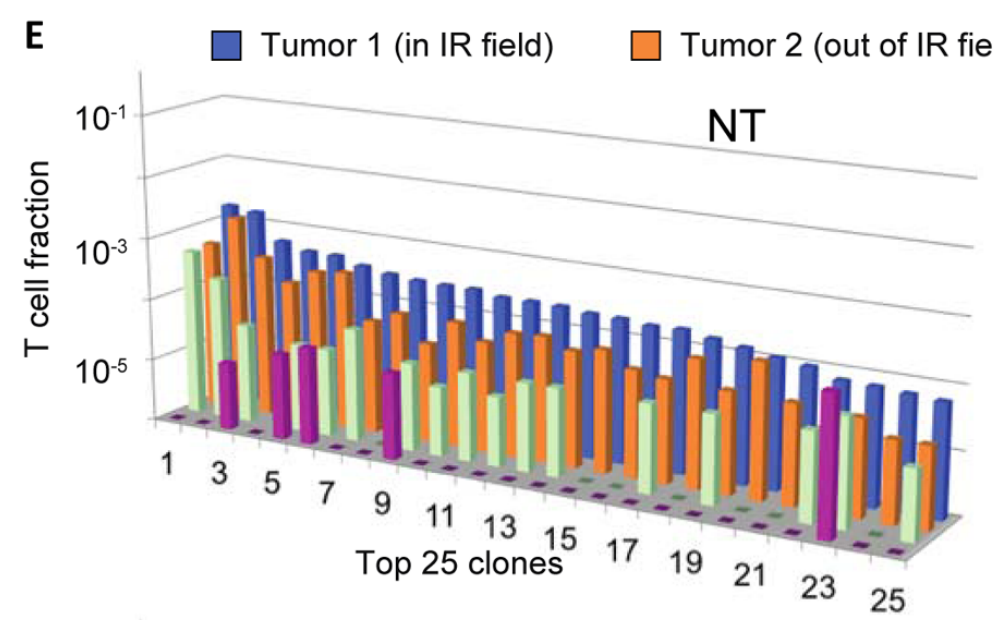
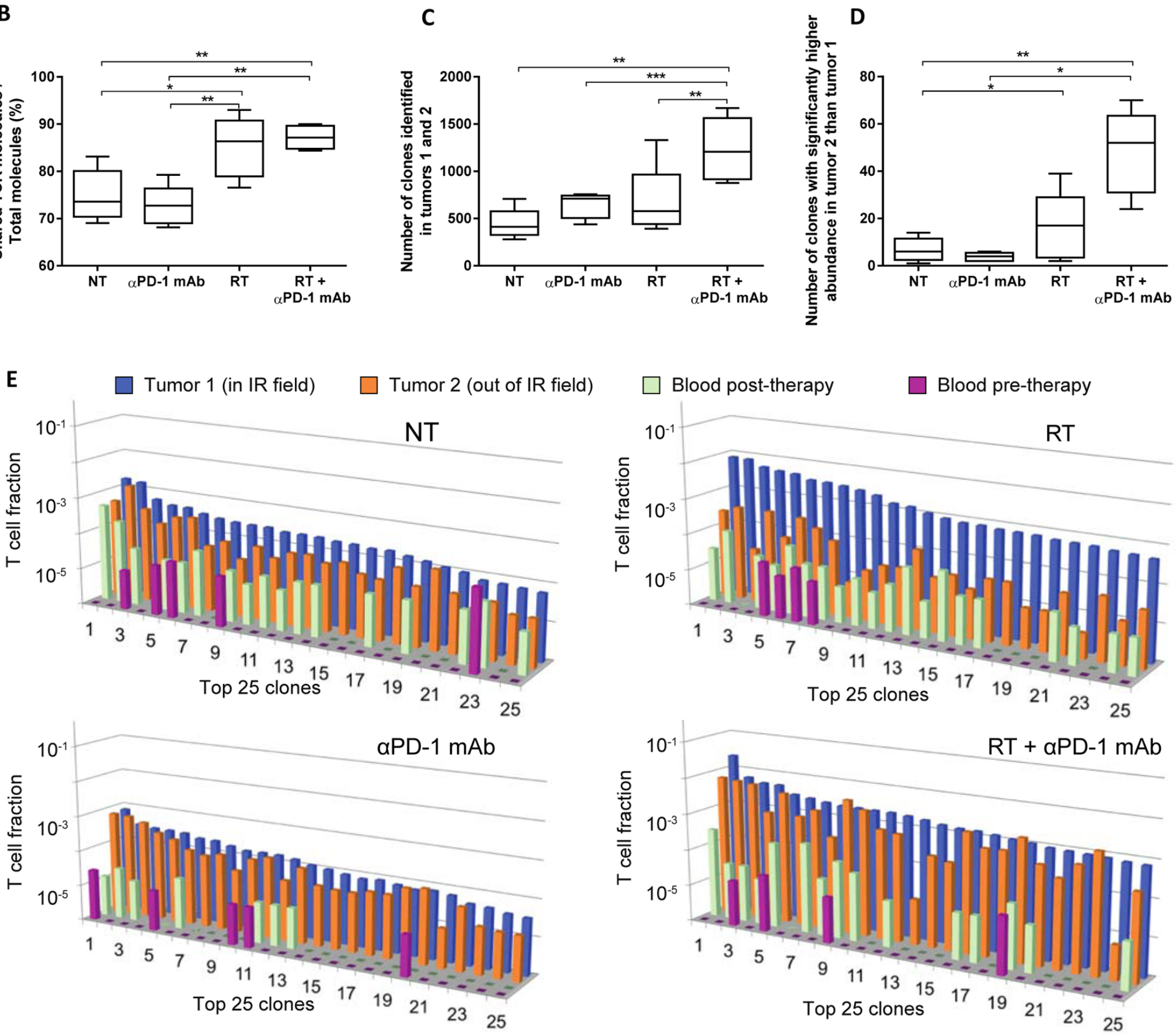

Figure 3 
A S.c. implantation of tumor Day 1
Treatment with

5 fractions of 2 Gy $R T$

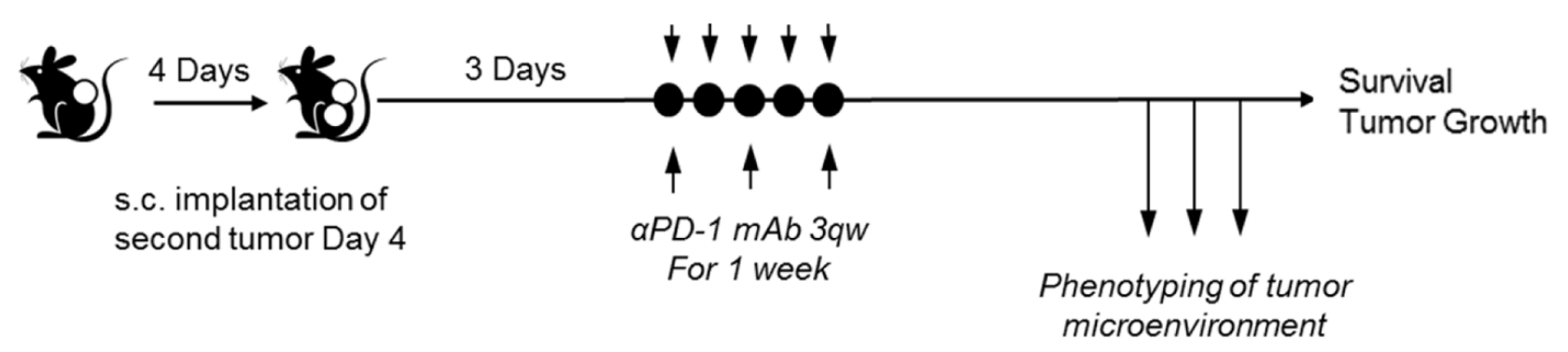

B

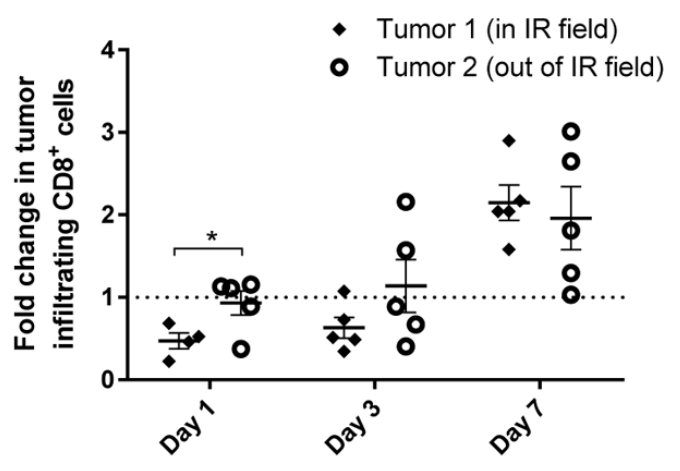

Time post last fraction of RT

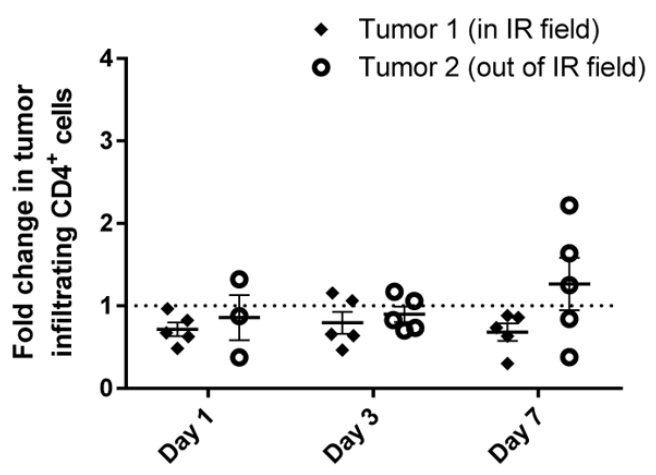

Time post last fraction of RT

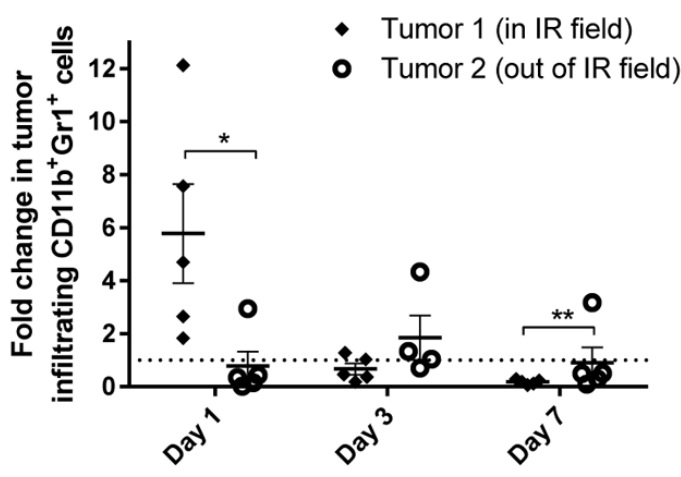

Time post last fraction of RT

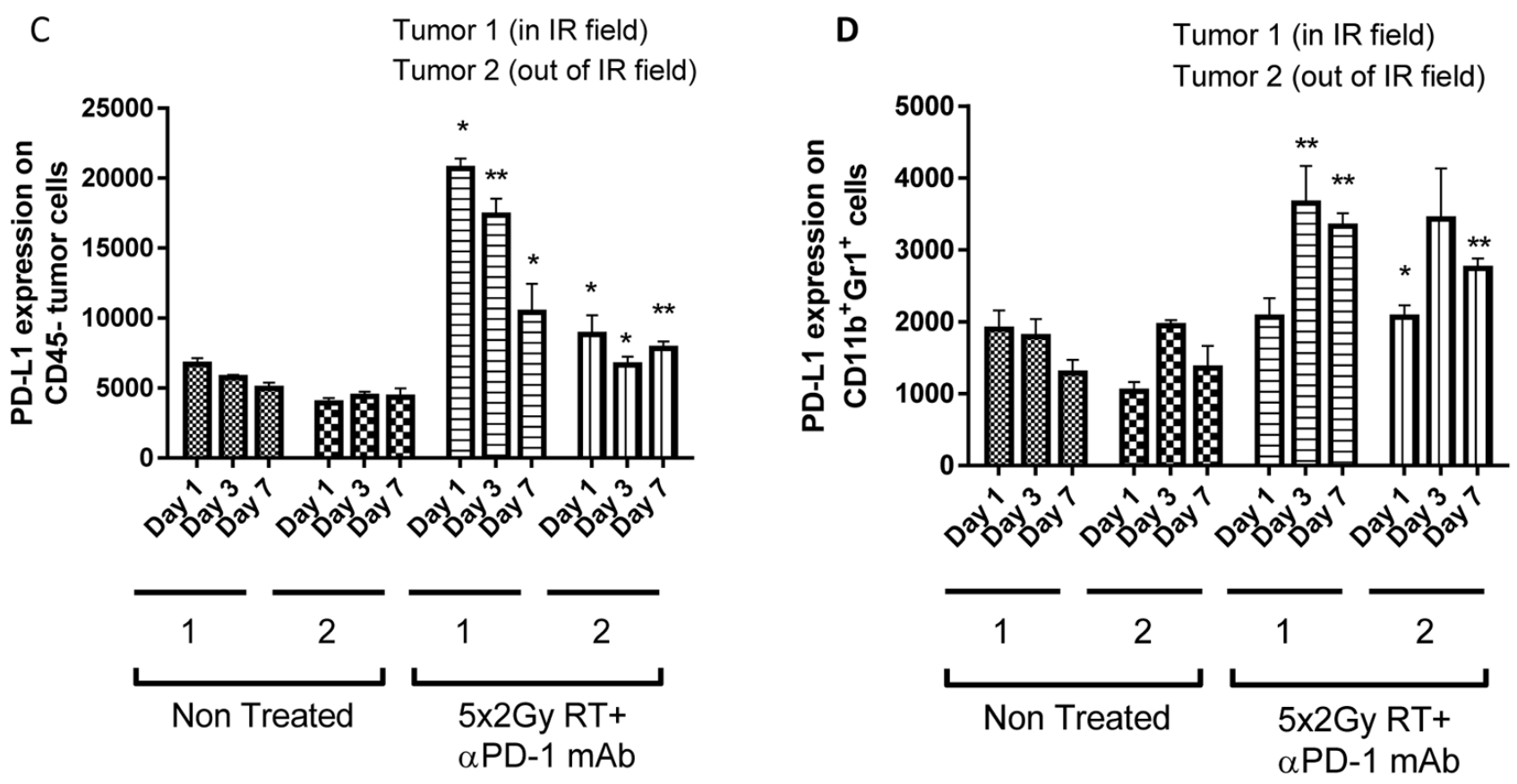

Figure 5 
Author Manuscript Published OnlineFirst on May 22, 2017; DOI: 10.1158/1078-0432.CCR-16-1673

Author manuscripts have been peer reviewed and accepted for publication but have not yet been edited.

A
s.c. implantation of
tumor Day 1
5 fractions of 2 Gy $R T$ Treatment with

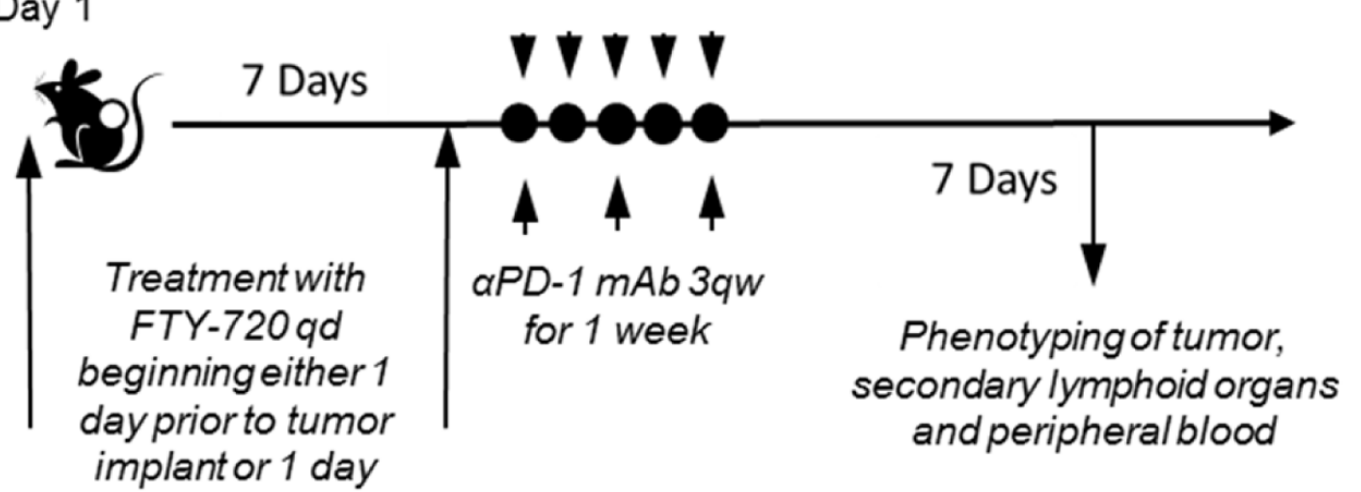

B

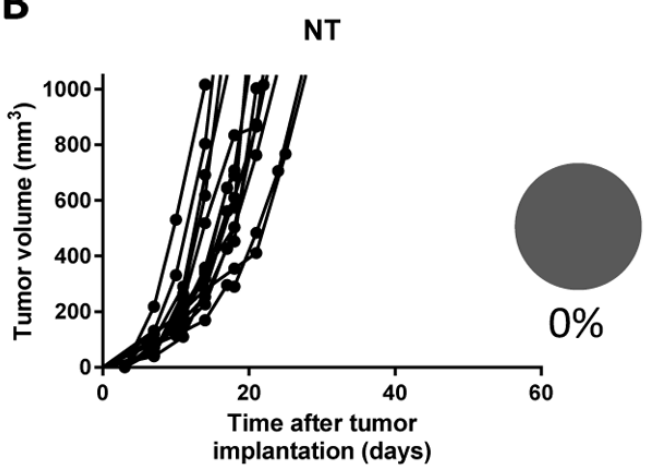

$5 \times 2$ Gy $+\alpha P D-1$ mAb

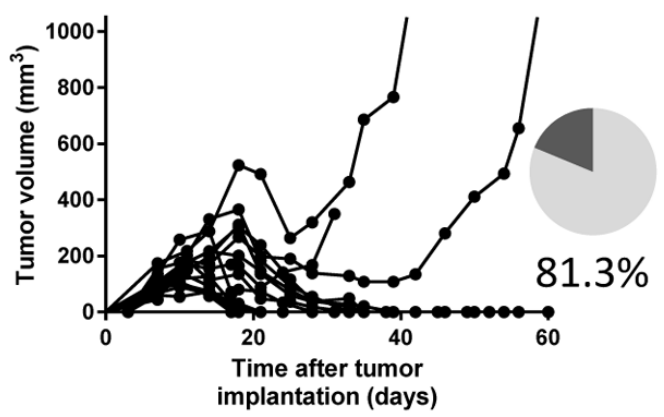

C

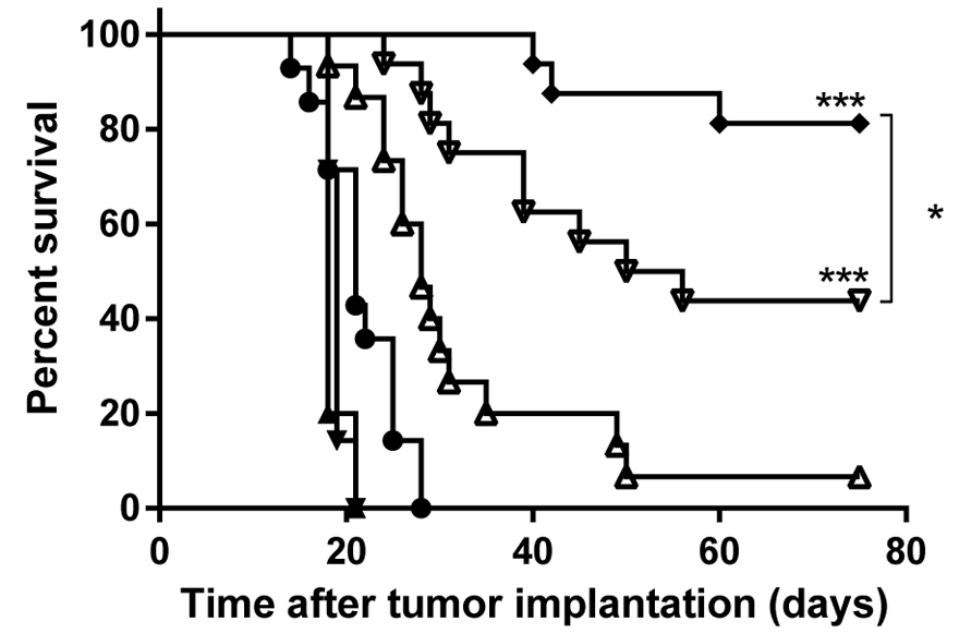

FTY720

(starting day-1)

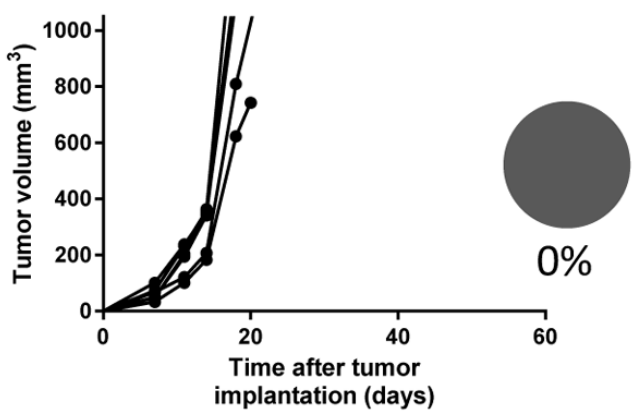

$5 \times 2$ Gy $+\alpha$ PD-1 mAb

+ FTY720 starting day-1
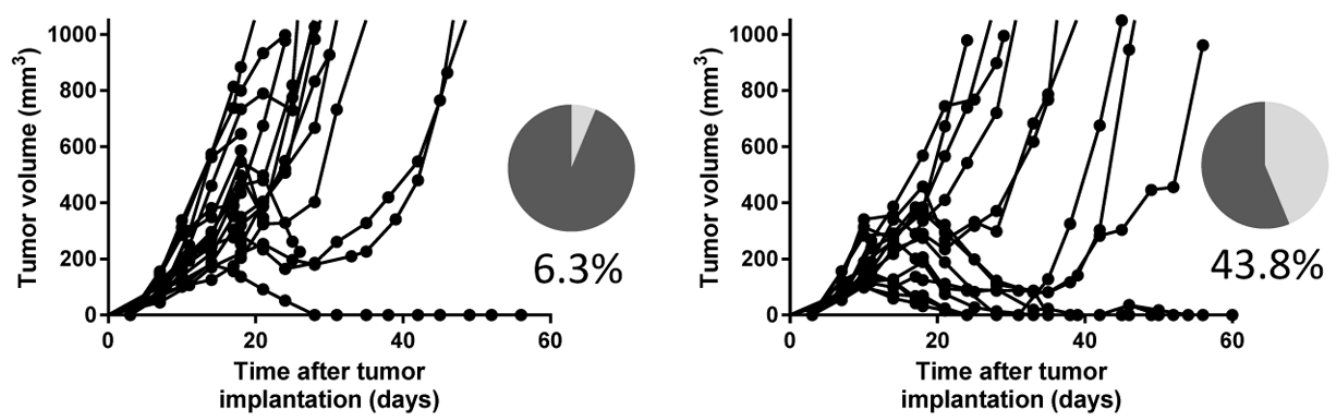

FTY720

(starting day 6)

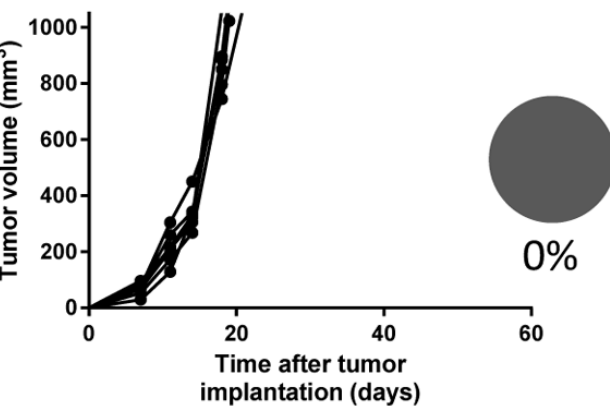

$5 \times 2$ Gy $+\alpha$ PD-1 mAb + FTY720 starting day 6

implantation (days)

Figure 6

$\rightarrow \mathrm{NT}$

FTY-720 qd

(starting day-1 wrt implant)

FTY-720 qd

(starting day-1 wrt Tx)

$\rightarrow$ 5x2Gy RT + $\alpha$ PD-1 mAb 10 mg/kg

$\triangle \mathrm{RT}+\alpha \mathrm{PD}-1 \mathrm{mAb}+$

FTY-720 (starting day-1 wrt implant)

$\rightarrow$ RT + $\alpha$ PD-1 mAb +

FTY-720 (starting day-1 wrt Tx) 


\section{Clinical Cancer Research}

\section{Fractionated radiation therapy stimulates anti-tumor immunity mediated by both resident and infiltrating polyclonal T-cell populations when combined with PD1 blockade}

Simon J Dovedi, Eleanor J Cheadle, Amy Popple, et al.

Clin Cancer Res Published OnlineFirst May 22, 2017. $\begin{array}{ll}\text { Updated version } & \begin{array}{l}\text { Access the most recent version of this article at: } \\ \text { doi:10.1158/1078-0432.CCR-16-1673 }\end{array}\end{array}$

Supplementary Access the most recent supplemental material at:

Material http://clincancerres.aacrjournals.org/content/suppl/2017/05/20/1078-0432.CCR-16-1673.DC1

Author Author manuscripts have been peer reviewed and accepted for publication but have not yet been Manuscript edited.

\section{E-mail alerts Sign up to receive free email-alerts related to this article or journal.}

Reprints and To order reprints of this article or to subscribe to the journal, contact the AACR Publications Subscriptions Department at pubs@aacr.org.

Permissions To request permission to re-use all or part of this article, contact the AACR Publications Department at permissions@aacr.org. 